\title{
Role of Heat Shock Protein 47 in Transdifferentiation of Human Tenon's Fibroblasts to Myofibroblasts
}

\author{
Samin Hong ${ }^{1}$, Kyoungsoo Park ${ }^{1,2}$, Jin Hyoung Kim ${ }^{1}$, Sueng-Han Han ${ }^{1}$, Jong Bok Lee ${ }^{1}$ and Gong Je Seong ${ }^{1 *}$
}

\begin{abstract}
Background: Heat shock protein 47 (Hsp47) is a well-known molecular chaperone in collagen synthesis and maturation. The aim of this study is to investigate its putative role in the transdifferentiation of Tenon's fibroblasts to myofibroblasts.

Methods: Primary cultured human Tenon's fibroblasts were exposed to transforming growth factor- $\beta 1$ (TGF- $\beta 1$ ) for up to 48 hours. The mRNA levels of Hsp47 and a smooth muscle actin (aSMA) were determined by quantitative real time RT-PCR. After delivery of small interfering RNA (siRNA) molecules targeting Hsp47 into the cells, the expression of Hsp47 and aSMA proteins was determined by western immunoblotting.

Results: TGF- $\beta 1$ increased the mRNA expressions of both Hsp47 and aSMA in human Tenon's fibroblasts, as determined by quantitative real time RT-PCR. However, it induced the protein expression of only aSMA but not Hsp47, as determined by western immunoblots. When siRNAs specific for Hsp47 were introduced into those cells, the TGF- $\beta 1$-induced expression of aSMA was significantly attenuated on western immunoblots; after 48 hours of exposure to TGF- $\beta 1$, the relative densities of immunobands were 11.58 for the TGF- $\beta 1$ only group and 2.75 for the siRNA treatment group, compared with the no treatment control group $(p<0.001)$.
\end{abstract}

Conclusions: Our data suggest that Hsp47 may be related to the TGF- $\beta 1$-induced transdifferentiation of human Tenon's fibroblasts to myofibroblasts.

Keywords: Fibroblast, Fibrosis, Heat shock protein, Myofibroblast, Transforming growth factor- $\beta$

\section{Background}

Excessive subconjunctival fibrosis is a major cause of failure after glaucoma filtering surgeries [1]. Although transforming growth factor- $\beta$ (TGF- $\beta$ ) is known to play a crucial role in this pathologic process and to induce the transdifferentiation of subconjunctival fibroblasts to myofibroblasts [2-5], the precise molecular mechanisms involved are not fully understood.

Heat shock protein 47 (Hsp47), also known as serpinh1 and collagen binding protein 1 , is a member of the serpin superfamily of serine protease inhibitors and a molecular chaperone specific for procollagen [6-11]. It localizes to the endoplasmic reticulum (ER) and is

\footnotetext{
* Correspondence: gjseong@yuhs.ac

'Institute of Vision Research, Department of Ophthalmology, Yonsei University College of Medicine, 50 Yonsei-ro, Seodaemun-gu, Seoul 120-752, Republic of Korea

Full list of author information is available at the end of the article
}

involved in the post-translational modification of procollagen and maturation of collagen. Although a number of studies have found overexpression of Hsp47 in extraocular tissues in various fibroblastic diseases [12-21], only a few studies have investigated Hsp47 expression in ocular tissue [22-24].

In the present study, we assessed whether TGF- $\beta$ increases Hsp47 expression in primary cultured human Tenon's fibroblasts and whether Hsp47 is associated with the TGF- $\beta$-induced expression of $\alpha$ smooth muscle actin ( $\alpha \mathrm{SMA})$, a phenotypic hallmark of the transdifferentiation of fibroblasts to myofibroblasts.

\section{Materials and methods}

Cell culture and exposure to TGF- $\beta 1$

After obtaining approval from the Institutional Review Board of our institution, subjects who had no ocular/ 
systemic disease except for strabismus received comprehensive information and provided written informed consent. All protocols were conducted in compliance with the tenets of the Declaration of Helsinki. Small Tenon's capsule specimens were excised during strabismus surgeries and fibroblasts were isolated as previously described [5]. Cells were incubated in Dulbecco's modified Eagle's medium (DMEM; Life Technologies, Carlsbad, CA, USA) supplemented with $10 \%$ heat-inactivated fetal bovine serum (FBS; Life Technologies), 100 units $/ \mathrm{mL}$ penicillin and $100 \mu \mathrm{g} / \mathrm{mL}$ streptomycin (Life Technologies) at $37^{\circ} \mathrm{C}$ and $5 \% \mathrm{CO}_{2}$. We used cells between the third and fifth passages for this study, and cultures were allowed to reach about $80 \%$ confluence.

After 12 hours of serum starvation in serum-free media, fibroblasts were exposed to $5 \mathrm{ng} / \mathrm{mL}$ recombinant human TGF- $\beta 1$ (R\&D Systems, Inc., Minneapolis, $\mathrm{MN}$, USA) for up to 48 hours. For the no treatment control group, the same volume of DMEM was added to the culture media instead of TGF- $\beta 1$. All experiments were performed in quadruplicate at least, and repeated at least four times using independent cell cultures.

\section{RNA interference assay}

Small interfering RNA (siRNA) molecules targeting Hsp47 mRNA were purchased from Santa Cruz Biotechnology, Inc. (Santa Cruz, CA, USA) and delivered into cells according to the manufacturer's instructions. Briefly, the cells were seeded in 6-well culture plates at $\sim 1.5 \times 10^{5}$ cells per well in antibiotic-free DMEM. The $50 \mathrm{nM}$ siRNA duplex was mixed with $2 \mu \mathrm{g} / \mathrm{mL}$ Lipofectamine $^{\mathrm{TM}} 2000$ (Life Technologies) to allow the formation of transfection complexes. This mixture was then dispensed onto the cells and incubated for 16 hours at $37^{\circ} \mathrm{C}$ in a $\mathrm{CO}_{2}$ incubator. For negative control, the scrambled siRNAs were used instead of the siRNAs specific for Hsp47.

\section{Real time RT-PCR}

Total RNA was extracted using RNeasy Mini Kit (QIAGEN, Venlo, Netherlands) and treated with DNase (QIAGEN) to remove contaminating DNA according to the manufacturer's directions. cDNA was synthesized from $2 \mu \mathrm{g}$ of total RNA using SuperScript ${ }^{\mathrm{TM}}$ III FirstStrand Synthesis System for RT-PCR (Life Technologies).

Real time RT-PCR was performed with $50 \mathrm{ng}$ cDNA per reaction using $25 \mu \mathrm{L}$ of iQ $S_{Y B R}{ }^{\circledR}$ Green Supermix (Bio-Rad Laboratories, Hercules, CA, USA) containing $500 \mathrm{nM}$ specific upstream and downstream primers (Table 1) in the iCycler $\mathrm{iQ}^{\mathrm{TM}}$ Real-Time PCR Detection System (Bio-Rad Laboratories). The SYBR green data and level of target mRNA were analyzed by iCycler $\mathrm{iQ}^{\mathrm{TM}}$ software with a relative ratio to $\beta$-actin of no treatment control.
Table 1 Primer sequence for real time RT-PCR

\begin{tabular}{|c|c|c|}
\hline Gene Name & Type & Sequence \\
\hline \multirow[t]{2}{*}{ Hsp47 } & Forward & 5'-CGC CAT GTT CTT CAA GCC A-3' \\
\hline & Reverse & 5'-CAT GAA GCC ACG GTT GTC C-3' \\
\hline \multirow[t]{2}{*}{ aSMA } & Forward & 5'-GTG TTA TGT AGC TCT GGA CTT TGA AAA-3' \\
\hline & Reverse & 5'-GGC AGC GGA AAC GTT CAT T-3' \\
\hline \multirow[t]{2}{*}{$\beta$-actin } & Forward & 5'-GCG GGA AAT CGT GCG TGA CAT T-3' \\
\hline & Reverse & 5'-GAT GGA GTT GAA GGT AGT TTC GTG-3' \\
\hline
\end{tabular}

aSMA = a smooth muscle actin; $\mathrm{Hsp} 47$ = heat shock protein 47.

\section{Western immunoblots}

Whole cellular proteins were extracted from primary cultured human Tenon's fibroblasts. Briefly, total cell lysates were obtained using cell lysis buffer (SigmaAldrich, St. Louis, MO, USA) on ice for 10 minutes. The lysates were sonicated and the cell homogenates were centrifuged at $15,000 \mathrm{~g}$ for 10 minutes at $4^{\circ} \mathrm{C}$.

Protein concentrations in the resultant supernatants were determined with the Bio-Rad Protein Assay (BioRad Laboratories) based on the Bradford dye-binding procedure. Equal amounts of protein $(10 \mu \mathrm{g})$ were boiled in Laemmli sample buffer and resolved by 7.5 or $12.0 \%$ sodium dodecyl sulfate polyacrylamide gel electrophoresis (SDS-PAGE). The proteins were transferred to polyvinylidene fluoride (PVDF) membranes and probed overnight with primary antibodies against human Hsp47, $\alpha$ SMA, and $\beta$-actin (diluted 1:500; Santa Cruz Biotechnology).

Immunoreactive bands were detected with horseradish peroxidase-conjugated secondary antibodies (diluted 1:2,000; Santa Cruz Biotechnology) and visualized by an enhanced chemiluminescent system (SuperSignal West Pico Chemiluminescent Substrates, Pierce Biotechnology, Inc., Rockford, IL, USA) on autoradiograph films.

\section{Statistical analysis}

Data are expressed as means \pm standard error of the mean (S.E.M.). Data were compared using KruskalWallis one-way analysis of variance using the MedCalc program for Windows, version 11.4.2.0 (MedCalc Software bvba, Mariakerke, Belgium). P-values less than 0.05 were considered statistically significant.

\section{Results}

Quantitative data of real time RT-PCR for Hsp47 and aSMA are shown in Figure 1. In human Tenon's fibroblasts, the mRNA levels of Hsp47 and $\alpha$ SMA were significantly increased at 16 hours after exposure to TGF- $\beta 1$. At that time point, the ratios relative to the control were $9.822 \pm 0.821$ for Hsp47 and $24.910 \pm 1.126$ for $\alpha$ SMA. The mRNA level of $\alpha$ SMA was dramatically increased as time passed, but that of Hsp47 was returned to baseline after 48 hours exposure to TGF- $\beta 1$. 


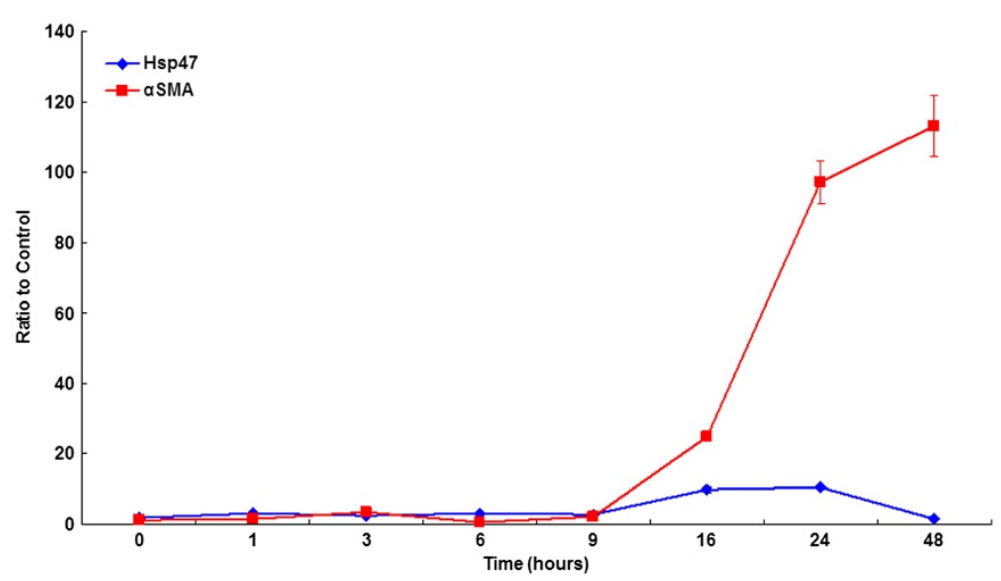

Figure 1 Quantitative real time RT-PCR for heat shock protein $47(\mathrm{Hsp} 47)$ and a smooth muscle actin (aSMA) after exposure to transforming growth factor- $\beta 1$ (TGF- $\beta 1$ ) for up to $\mathbf{4 8}$ hours. The level of target mRNA was calculated using a relative ratio to $\beta$-actin of no treatment control and expressed as the mean \pm S.E.M. ( $n=16$ for each group).

The effects of TGF- $\beta 1$ and siRNAs specific for Hsp47 on $\alpha$ SMA expression are shown using by time sequential western immunoblots (Figure 2). The expression of Hsp47 was not obviously changed by TGF- $\beta 1$ treatment, whereas the expression of $\alpha \mathrm{SMA}$ was significantly increased after 48 hours of TGF- $\beta 1$ treatment $(\mathrm{p}=0.011)$. When siRNA molecules targeting Hsp47 were introduced, the TGF- $\beta 1$-induced $\alpha$ SMA expression was significantly attenuated, as was Hsp47 expression. After treatment with TGF- $\beta 1$ for 48 hours, the ratio of $\alpha$ SMA immunobands relative to control was $1.52 \pm 0.06,34.39 \pm 18.47$, $8.18 \pm 2.52$ for the no treatment group, TGF- $\beta 1$ treatment only group, and Hsp47 siRNA and TGF- $\beta 1$ treatment group, respectively $(\mathrm{p}<0.001)$. To eliminate the possible impact of transfection itself, scrambled siRNAs were also used (Additional file 1). Presence of scrambled siRNAs did not make any apparent influence to the response of human Tenon's fibroblasts caused by TGF- $\beta 1$ treatment.

\section{Discussion}

In most living tissues, fibrosis is an essential woundhealing response to noxious stimuli. If excessive, however, it can disrupt the normal function of affected organs. For subconjunctival fibrosis, TGF- $\beta$ plays a crucial role and

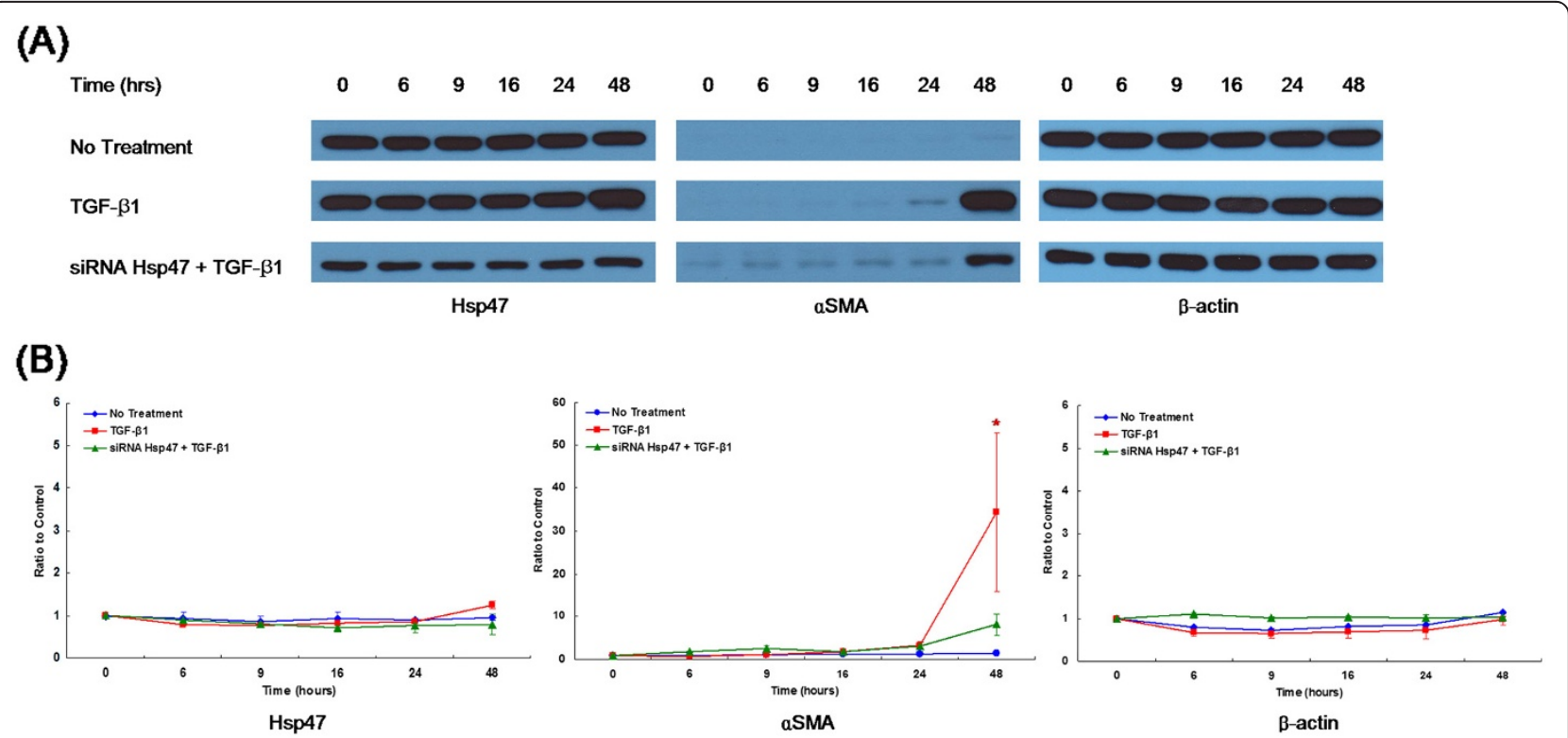

Figure 2 Representative sequential bands of western immunoblots (A) and densitometric data (B) for heat shock protein 47 (Hsp47), a smooth muscle actin (aSMA), and $\beta$-actin. Human Tenon's fibroblasts were exposed to transforming growth factor- $\beta 1$ (TGF- $\beta 1$ ) for up to 48 hours with or without siRNAs targeting Hsp47. The densitometric data are expressed as the mean \pm S.E.M. $\left(n=16\right.$ for each group) ${ }^{*} p<0.001$. 
causes the transdifferentiation of Tenon's fibroblasts to myofibroblasts and the subsequent production of extracellular matrix including collagen from the transdifferentiated myofibroblasts [2-5].

Hsp47 is a $47-\mathrm{kDa}$ glycoprotein and specialized molecular chaperone in collagen biosynthesis. In the ER of any collagen-producing cells, Hsp47 binds to the triple helical procollagen and stabilizes its higher-order structure. It prevents the premature secretion of procollagens from the ER into the Golgi apparatus and concentrates them within the ER before finishing their maturation process [6-11]. The importance of Hsp47 in normal development was documented by Nagai et al. [10]. Using Hsp47 knockout mice, they showed that disruption of Hsp47 caused severe deficiencies in collagen maturation and organogenesis. The Hsp47 null embryos did not develop beyond 11.5 days postcoitus. In some animal models, siRNAs targeting Hsp47 effectively reduced experimental fibrosis $[25,26]$.

The majority of previous studies have focused on the role of Hsp47 in collagen synthesis. However, in the present study using TGF- $\beta$-stimulated human Tenon's fibroblasts in vitro, we noticed another putative role of Hsp47 in the fibrotic process. The silencing of Hsp47 with specific siRNA molecules significantly attenuated the expression of $\alpha \mathrm{SMA}$ that was induced by TGF- $\beta 1$ treatment. Our data imply that Hsp47 may be involved in the initial stage of fibrosis, the transdifferentiation of stressed fibroblasts to myofibroblasts, as well as the later stage of fibrosis, the collagen synthesis in already transdifferentiated myofibroblasts. Since the transdifferentiation of fibroblasts to myofibroblasts is thought to be a vital initial step for the whole fibrotic process, if Hsp47 directly or indirectly participates in this step, controlling its action might be a novel therapeutic strategy for patients suffering from excessive fibrosis. Actually, the Hsp47-associated transdifferentiation signaling may be not the major pathway in pathologic fibrotic processes. However, due to the fibrosis is the essential wound healing processes, its partial modification using Hsp47 pathway rather than complete suppression might be a better option to control the postoperative inflammation. To better understand the precise working mechanisms of Hsp47 in transdifferentiation of fibroblasts to myofibroblasts, the further investigations are needed.

Regarding expression of Hsp47 itself, our findings differ from previous reports that documented increased expression of Hsp47 in various extraocular fibrotic diseases [12-21]. Increased expression of Hsp47 was even reported in ocular cicatrical pemphigoid [22]. However, in this in vitro study using human Tenon's fibroblasts, TGF- $\beta 1$ increased the mRNA expression of Hsp47 but did not influence its protein expression. Data of immunofluorescence staining (Additional file 2) support the results of western immunoblots. Though fibroblasts have been considered universal cells, they have different characteristics depending on their origin [27]. Their response to TGF- $\beta 1$ and expression pattern of Hsp47 are able to be tissue-specific and/or disease-specific. In addition, a gap between mRNA and protein levels of Hsp47 is assumed to be caused by the post-transcriptional modulation.

\section{Conclusion}

In summary, Hsp47, a well-known molecular chaperone specific for procollagen, appears to be related to the TGF- $\beta 1$-induced transdifferentiation of human Tenon's fibroblasts to myofibroblasts.

\section{Additional files}

\section{Additional file 1: Western immunoblots of the scrambled} siRNA-introduced fibroblasts for heat shock protein 47 (Hsp47) (A), a smooth muscle actin (aSMA) (B), and $\beta$-actin (C). siRNA $\mathrm{SC}=$ scrambled siRNA; TGF- $\beta 1=$ transforming growth factor- $\beta 1$.

Additional file 2: Immunefluorescence of human Tenon's fibroblasts for heat shock protein 47 (Hsp47). (A) No treatment control; (B) TGF- $\beta 1$ treatment. Nuclei were counterstained with 4',6-diamidino-2-phenylindole (DAPI).

\section{Abbreviations}

aSMA: a Smooth Muscle Actin; DMEM: Dulbecco's Modified Eagle's Medium; ER: Endoplasmic Reticulum; FBS: Fetal Bovine Serum; Hsp47: Heat shock protein 47; PVDF: Polyvinylidene Fluoride; SDS-PAGE: Sulfate Polyacrylamide Gel Electrphoresis; S.E.M.: Standard Error of the Mean; siRNA: small interfering RNA; TGF- $\beta$ : Transforming Growth Factor- $\beta$.

\section{Competing interests}

None of authors has a financial competing interest.

\section{Authors' contributions}

GJS, SH, and JBL designed the experiments; SH, KP, JHK, SHH carried out the molecular works; All authors were involved in interpretation of data and writing of manuscript. All authors read and approved the final manuscript.

\section{Acknowledgement}

This work was supported by the Health Fellowship Foundation, Seoul, Republic of Korea.

\section{Author details}

${ }^{1}$ Institute of Vision Research, Department of Ophthalmology, Yonsei University College of Medicine, 50 Yonsei-ro, Seodaemun-gu, Seoul 120-752, Republic of Korea. ${ }^{2}$ Siloam Eye Hospital, 181 Deungchon-ro, Gangseo-gu, Seoul 156-032, Republic of Korea.

Received: 5 October 2011 Accepted: 30 August 2012 Published: 11 September 2012

\section{References}

1. Skuta GL, Parrish RK 2nd: Wound healing in glaucoma filtering surgery. Surv Ophthalmol 1987, 32:149-170.

2. Cordeiro MF, Bhattacharya SS, Schultz GS, Khaw PT: TGF-beta1, -beta2, and -beta3 in vitro: biphasic effects on Tenon's fibroblast contraction, proliferation, and migration. Invest Ophthalmo/ Vis Sci 2000, 41:756-763.

3. Meyer-Ter-Vehn T, Grehn F, Schlunck G: Localization of TGF-beta type II receptor and ED-A fibronectin in normal conjunctiva and failed filtering blebs. Mol Vis 2008, 14:136-141.

4. Saika S, Yamanaka O, Sumioka T, et al: Fibrotic disorders in the eye: targets of gene therapy. Prog Retin Eye Res 2008, 27:177-196. 
5. Seong GJ, Hong S, Jung SA, et al: TGF-beta-induced interleukin-6 participates in transdifferentiation of human Tenon's fibroblasts to myofibroblasts. Mol Vis 2009, 15:2123-2128

6. Nagata K: Expression and function of heat shock protein 47: a collagenspecific molecular chaperone in the endoplasmic reticulum. Matrix Biol 1998, 16:379-386

7. Lamandé SR, Bateman JF: Procollagen folding and assembly: the role of endoplasmic reticulum enzymes and molecular chaperones. Semin Cell Dev Biol 1999, 10:455-464.

8. Razzaque MS, Taguchi T: The possible role of colligin/HSP47, a collagenbinding protein, in the pathogenesis of human and experimental fibrotic diseases. Histol Histopathol 1999, 14:1199-1212.

9. Hendershot LM, Bulleid NJ: Protein-specific chaperones: the role of hsp47 begins to gel. Curr Biol 2000, 10:R912-R915.

10. Nagai N, Hosokawa M, Itohara S, et al: Embryonic lethality of molecular chaperone hsp47 knockout mice is associated with defects in collagen biosynthesis. J Cell Biol 2000, 150:1499-1506.

11. Makareeva E, Leikin S: Procollagen triple helix assembly: an unconventional chaperone-assisted folding paradigm. PLoS One 2007, 2:e1029.

12. Takeda K, Kusachi S, Ohnishi H, et al: Greater than normal expression of the collagen-binding stress protein heat-shock protein- 47 in the infarct zone in rats after experimentally-induced myocardial infarction. Coron Artery Dis 2000, 11:57-68.

13. Tsukimi Y, Okabe S: Recent advances in gastrointestinal pathophysiology: role of heat shock proteins in mucosal defense and ulcer healing. Biol Pharm Bull 2001, 24:1-9.

14. Kakugawa T, Mukae H, Hayashi T, et al: Expression of HSP47 in usual interstitial pneumonia and nonspecific interstitial pneumonia. Respir Res 2005, 6:57.

15. Razzaque MS, Le VT, Taguchi T: Heat shock protein 47 and renal fibrogenesis. Contrib Nephrol 2005, 148:57-69.

16. Hirai K, Kikuchi S, Kurita A, et al: Immunohistochemical distribution of heat shock protein 47 (HSP47) in scirrhous carcinoma of the stomach. Anticancer Res 2006, 26:71-78.

17. Chen JJ, Zhao S, Cen Y, et al: Effect of heat shock protein 47 on collagen accumulation in keloid fibroblast cells. Br J Dermatol 2007, 156:1188-1195.

18. Díaz R, Kim JW, Hui JJ, et al: Evidence for the epithelial to mesenchymal transition in biliary atresia fibrosis. Hum Pathol 2008, 39:102-115.

19. Araki K, Mikami T, Yoshida T, et al: High expression of HSP47 in ulcerative colitis-associated carcinomas: proteomic approach. Br J Cancer 2009, 101:492-497.

20. Chang $T Y$, Tsai $\mathrm{CH}$, Chang YC: The upregulation of heat shock protein 47 in human gingival fibroblasts stimulated with cyclosporine A. $J$ Periodontal Res 2010, 45:317-322.

21. Christiansen HE, Schwarze U, Pyott SM, et al: Homozygosity for a missense mutation in SERPINH1, which encodes the collagen chaperone protein HSP47, results in severe recessive osteogenesis imperfecta. Am J Hum Genet 2010, 86:389-398.

22. Foster CS, Sainz De La Maza M: Ocular cicatricial pemphigoid review. Curr Opin Allergy Clin Immunol 2004, 4:435-439.

23. Ogawa $Y$, Razzaque MS, Kameyama K, et al: Role of heat shock protein 47 , a collagen-binding chaperone, in lacrimal gland pathology in patients with cGVHD. Invest Ophthalmol Vis Sci 2007, 48:1079-1086.

24. Yu AL, Moriniere J, Birke M, et al: Reactivation of optic nerve head astrocytes by TGF-beta2 and $\mathrm{H} 2 \mathrm{O} 2$ is accompanied by increased $\mathrm{Hsp} 32$ and Hsp47 expression. Invest Ophthalmol Vis Sci 2009, 50:1707-1717.

25. Wang Z, Li L: Adenovirus-mediated RNA interference against collagenspecific molecular chaperone 47-KDa heat shock protein suppresses scar formation on mouse wounds. Cell Biol Int 2008, 32:484-493.

26. Xia Z, Abe K, Furusu A, et al: Suppression of renal tubulointerstitial fibrosis by small interfering RNA targeting heat shock protein 47 . Am J Nephrol 2008, 28:34-46.

27. Xi X, McMillan DH, Lehmann GM, et al: Ocular fibroblast diversity: implications for inflammation and ocular wound healing. Invest Ophthalmol Vis Sci 2011, 52:4859-4865.

doi:10.1186/1471-2415-12-49

Cite this article as: Hong et al: Role of Heat Shock Protein 47 in Transdifferentiation of Human Tenon's Fibroblasts to Myofibroblasts. BMC Ophthalmology 2012 12:49.

\section{Submit your next manuscript to BioMed Central and take full advantage of:}

- Convenient online submission

- Thorough peer review

- No space constraints or color figure charges

- Immediate publication on acceptance

- Inclusion in PubMed, CAS, Scopus and Google Scholar

- Research which is freely available for redistribution 